\title{
A ESPACIALIZAÇÃO DA CULTURA E AS TERRITORIALIDADES QUILOMBOLAS NO ESTADO DO RIO GRANDE DO NORTE, BRASIL
}

\author{
CULTURAL SPATIALIZATION AND QUILOMBOLA TERRITORIALITIES \\ IN THE BRAZILIAN STATE OF RIO GRANDE DO NORT
}

\author{
ESPACIALIZACION DE LA CULTURA Y LAS TERRITORIALIDADES \\ QUILOMBOLAS EN EL ESTADO DE RIO GRANDE DO NORTE EN BRASIL
}

\section{Camila Silva Pereira}

Mestre em Geografia pela Universidade Federal do Rio Grande do Norte. Centro de Ciências Humanas, Letras e Artes. Departamento de Geografia.

UFRN.CCHLA. Campus Universitário, s/n. Lagoa Nova. Natal. Rio Grande do Norte-Brasil. CEP: 59.078-970. E.mail: camilasilvageo@gmail.com

\section{Francisca Elizonete de Souza Lima}

Mestre em Geografia pela Universidade Federal do Rio Grande do Norte. Centro de CiênciasHumanas, Letras e Artes. Departamento de Geografia. UFRN.CCHLA. Campus Universitário, s/n. Lagoa Nova. Natal. Rio Grande do Norte - Brasil.CEP: 59.078-970.E.mail: lilielizonetesouza@gmail.com

\section{RESUMO}

Os estudos culturais passaram a ter maior espaço na Geografia após a consolidação da geografia cultural enquanto vertente de pesquisa que trata da análise das relações do homem no/com o espaço a partir dos significados atribuídos a este. De modo específico, estudos que abrangem a discussão acerca de comunidades tradicionais quilombolas e as diversas dimensões possíveis de serem analisadas, vêm ganhando espaço na Geografia nas últimas décadas. Compreender as aberturas da geografia cultural para o entendimento da espacialização dos fenômenos culturais e a manutenção das territorialidades quilombolas em comunidades dessa natureza, constitui o objetivo deste trabalho. A discussão está centrada no reconhecimento das representações simbólicas dos grupos tradicionais quilombolas, analisando-as em seu conteúdo político de permanência, mudanças e reafirmações na sociedade, de modo que a cultura dos grupos quilombolas do estado do Rio Grande do Norte seja percebida em contextos territoriais que, no entanto, não a desligam da lógica da cultura em uma contiguidade espacial.

Palavras-chave: Geografia Cultural. Territorialidades. Comunidades Quilombolas. Simbolismos. 


\begin{abstract}
Cultural studies now have more space in Geography after the consolidation of Cultural Geography as another form of research that deals with the analysis of the relations between men and space. Specifically, studies covering the discussion of traditional quilombola communities and the various possible dimensions to be analyzed, has gained space in geography in recent decades. Comprehending the openings of Cultural Geography in order to understand the spatial distribution of cultural phenomena and maintenance of territoriality in quilombola communities of this nature is the goal of this work. The discussion is focused on the recognition of symbolic representations of traditional quilombolas groups, analyzing them in their political content of permanence, restatements and changes in society, so that the culture of the quilombola groups of Rio Grande do Norte state is perceived in territorial contexts, that, however, do not turn off the logic of culture in a spatial contiguity
\end{abstract}

Keywords: Cultural Geography. Territorialities. Quilombo communities. Symbolisms.

\title{
RESUMEN
}

Los estudios culturales tienen ahora más cabida en Geografía después de la consolidación de la Geografía Cultural como otra forma de investigación que se ocupa del análisis de las relaciones del hombre en/con el espacio a partir de los significados atribuidos a este. En concreto, los estudios que abarcan la discusión de las comunidades tradicionales quilombolas y las diversas dimensiones posibles a ser analizadas, están ganando espacio en la geografía en las últimas décadas. La comprensión de las aberturas de la geografía cultural para el entendimiento de de la distribución espacial de los fenómenos culturales y el mantenimiento de las territorialidades quilombolas en comunidades de esa naturaleza, es el objetivo de este trabajo. La discusión se centra en el reconocimiento de las representaciones simbólicas de los grupos tradicionales quilombolas, analizándolas en su contenido político de permanencias, cambios y reajustes en la sociedad, de modo que la cultura de los grupos quilombolas del estado de Rio Grande do Norte se perciba en contextos territoriales, que sin embargo, no la desligan de la lógica de la cultura en una contigüidad espacial.

Palabras-clave: Geografía Cultural. Territorialidades. Comunidades quilombolas. Simbolismos. 


\section{INTRODUÇÃO}

Os estudos culturais sempre estiveram presentes nas discussões das várias Ciências Sociais e Humanas. Na Geografia, a abordagem cultural torna-se mais evidente nas análises a partir da década de 1970 e, desde então, vem abrindo espaço para a investigação de campos de estudo ainda pouco discutidos, como é o caso das comunidades tradicionais quilombolas.

Com base nas premissas apontadas, o trabalho apresentado tem como objetivo propor uma discussão sobre a espacialização dos fenômenos culturais e as territorialidades quilombolas em comunidades dessa natureza. A proposta é desenvolver reflexões para o reconhecimento das representações simbólicas dos grupos tradicionais, analisando-as em seu conteúdo político de permanência, mudanças e reafirmações na sociedade, de modo que a cultura dos grupos quilombolas do estado do Rio Grande do Norte seja percebida em contextos territoriais que, no entanto, não a desligam da lógica da cultura em uma contiguidade espacial.

A cultura de um modo geral enquanto produtora do território e dos sistemas simbólicos que perfazem as territorialidades dos grupos quilombolas, nos possibilita pensar as relações de poder que fragmentam ou unem os grupos e dão sentido às suas práticas sociais no território.

Baseamo-nos em discussões teóricas de autores como Claval (2006 e 2008) discutindo sobre geografia cultural, Haesbart (2009) trazendo concepções sobre território, territorialidade e territorialização, Ratts (2009) abordando as relações de poder no território, Castro (2006) e a discussão das simbologias dos lugares. Além de autores que discutem as manifestações culturais de grupos quilombolas no estado do Rio Grande do Norte, nos permitindo compreender a construção de suas territorialidades, são eles: Cavignac (2008), Gois (2006), Morais (2005), Pereira e Dozena (2014), entre outros que nortearam o traçado teórico da pesquisa.

Desse modo, iniciamos a discussão traçando caminhos para compreendermos a espacialização da cultura e sua materialização nos territórios a partir das abordagens da geografia cultural e, em seguida, discutimos as formas materiais e simbólicas que representam a territorialização e a manutenção das territorialidades em algumas comunidades quilombolas no Rio Grande do Norte. 


\section{A GEOGRAFIA CULTURAL E A CULTURA COMO ELEMENTO ESPACIAL}

A cultura sempre esteve embutida nas análises geográficas se pensarmos em seu caráter conceitual amplo, que abrange as relações humanas no espaço produzido através destas. Embora sempre tenha se feito presente na Geografia desde às concepções do possibilismo com os gêneros de vida ${ }^{1}$ de Vidal de La Blache, as abordagens culturais na Geografia estiveram associadas às concepções que culminaram na construção de uma geografia cultural diversificada até se estruturar naquilo que hoje alguns autores chamam de "nova geografia cultural".

Em sua constituição, a geografia cultural originada na Europa no final do século XIX e início do século XX, juntamente com a sistematização da Geografia enquanto ciência, esteve associada aos estudos da paisagem e da região. Ambas, em certa medida, limitavam as análises no sentido de que eram estudadas enquanto produtos dos traços culturais que davam forma às paisagens e diferenciavam as regiões. As análises ocorriam de modo superficial, dada as limitações de investigação em campo e o enrijecimento da ciência, dificultando as depreensões que contemplassem o estudo do espaço a partir da produção imaterial e simbólica que também o dava forma. De acordo com Claval (2006):

É preciso que a geografia cultural se torne uma reflexão sobre a geograficidade, ou seja, sobre o papel que o espaço e o meio têm na vida dos homens, sobre o sentido que eles lhes dão e sobre a maneira pela qual eles os utilizam para melhor se compreenderem e construírem seu ser profundo (CLAVAL, 2006, p.89-90).

O sentido do espaço produzido pelo homem e também meio influenciador das relações sociais, passa a ser compreendido sob o prisma das representações e do seu valor imaterial. Foi a partir da década de 1970, com o surgimento da corrente da geografia humanista cultural, que esse ramo da Geografia ganha uma conotação diferenciada. A fenomenologia ${ }^{3}$, corrente epistemológica do humanismo, foi fundamental nas transformações do fazer científico e nas novas formas de analisar as relações humanas. Até então, os conceitos mais discutidos ligados à geografia cultural eram o de paisagem e região. Com a descoberta

\footnotetext{
De acordo com Claval (2006), a noção de gênero de vida tem uma dimensão ecológica e naturalista, por mostrar como os grupos humanos se adaptam ao ambiente. No entanto, tem também uma dimensão social e cultural, por mostrar que os grupos podem se tornar fortes e, ao invés de se adaptar ao meio, eles procuram modificá-lo.

2 A nova geografia cultural caracteriza-se como uma vertente recente, estruturando-se no mundo na década de 1960 e no Brasil por volta de 1970. Nesta linha de pensamento, o foco de análise é o homem no contexto do espaço e a construção das representações neste, expressando o sentido da corporeidade através das materializações do corpo, como forma de expressar as desigualdades socioculturais, econômicas, políticas e espaciais características da sociedade e dos processos culturais de modo geral (CLAVAL, 2008).

3 Embora seja método de análise de vários campos da geografia, a fenomenologia contribuiu para os estudos culturais tendo em vista a sua abertura para o estudo das essências, das percepções humanas e de como o homem sente seu espaço vivido a partir das relações de afetividade construídas com/nele. Na concepção fenomenológica do mundo, o homem está inserido nos fenômenos que acontecem no mundo, e é parte fundamental nestes acontecimentos. Assim, a fenomenologia surgindo na Alemanha a partir dos estudos de Inmanel Kant, no final da idade moderna, rompe com o tradicionalismo cartesiano e debruça-se numa perspectiva nova do fazer filosófico, abrindo espaço para o estudo das essências (ALEXANDRE; OLIVEIRA, 2008).
} 
da filosofia fenomenológica na Geografia e, de modo específico, na geografia cultural, os conceitos de espaço, lugar e território expandem as possibilidades de análise das relações sociais no/com o espaço. Descreviam-se os objetos e buscava-se compreender o seu sentido para os homens e suas representações a partir da experiência do vivido.

A partir de 1990, em virtude das mudanças ocorridas nos âmbitos político, econômico, ambiental, entre outros, e, sobretudo pela expansão do capitalismo nos países socialistas após o fim da Guerra Fria em 1989, a geografia cultural, assim como os demais ramos das ciências e, de modo específico, as Ciências Humanas e Sociais, tiveram de renovar-se para contribuir na análise das transformações no/do espaço de modo mais aprofundado.

A cultura, enquanto forma de comportamento e aquisição de valores diferenciados adquiridos e (re)modelados na convivência em sociedade, necessitava, nesse novo contexto social, ser compreendida em sua dimensão geográfica enquanto fenômeno passível de ser espacializado. Concordamos com Zanatta ao afirmar que:

a cultura está intimamente ligada ao sistema de representações, de significados, de valores que criam uma identidade que se manifesta mediante construções compartilhadas socialmente e expressas espacialmente, ou seja, de admitir que a cultura no seu sentido antropológico mais amplo representa todo o modo de vida de uma sociedade, o que não inclui somente a produção de objetos materiais, mas um sistema cultural (valores morais, éticos, hábitos e significados expressos nas práticas sociais), um sistema simbólico (mitos e ritos unificadores) e um sistema imaginário, que serve de liame aos dois últimos, constituindo-se no lócus da construção da identidade espacial de um grupo (ZANATTA, 2007, p. 6 - 7).

Essa questão abriu espaço para que novos conceitos fossem também importantes para o enriquecimento das discussões. Não mais é possível estudar a cultura enquanto produtora do espaço somente considerando seus traços na paisagem e as ferramentas utilizadas na sua transformação, as diferenças e similitudes regionais. O conceito de território também ganha uma conotação diferenciada na nova geografia cultural, não abandonando seu caráter histórico enquanto lócus do poder, inicialmente voltado principalmente para as ações do Estado, mas adquirindo uma dimensão mais flexível de análise, com base no poder material e imaterial das representações e das simbologias construídas pelos sujeitos a partir de suas territorialidades. Segundo Claval, Bonnemaison, apud Ratts (2003) é a geografia cultural contemporânea que abre oportunidade para os estudos do território e das relações entre este a discussão de etnicidade.

A intenção não é fragmentar ou limitar a análise da espacialização das manifestações culturais às abrangências que os conceitos apresentados possuem. Longe de nossa discussão está o interesse de afirmar que, ao compor também elemento de estudo dos territórios, a cultura limita-se a esse campo de análise, haja vista o seu caráter difuso em níveis diferenciados 
na contiguidade espacial que abrange todas as dimensões conceituais apresentadas. Pensemos a cultura e sua representação em contextos territoriais, de modo que percebamos como se espacializa, material e simbolicamente, nos territórios quilombolas no estado do Rio Grande do Norte, influenciando na constituição e ressignificação de suas territorialidades.

A ressignificação das territorialidades dos grupos quilombolas apontam para que possamos reforçar o intento da desconstrução de concepções que relegam esses sujeitos a um distanciamento dos processos de ordem econômica, política e cultural mais ampla. À medida que esses grupos expandem as redes de sociabilidade nas quais estão inseridos e constituem parte de seu funcionamento, suas territorialidades expressam os processos de fragmentação e resistência de suas práticas culturais que, não necessariamente, permanece intactas do ponto de vista dos elementos festivos, mas resguardam valor simbólico que aponta para o fortalecimento dos grupos a partir daquilo que os aproxima. Conforme aponta Claval (1999):

\footnotetext{
Na concepção relacional da cultura, o indivíduo não a recebe como um conjunto já pronto: ele a constrói através das redes de contatos nas quais ele se acha inserido, e pelas quais recebe informações, códigos e sinais. A cultura na qual ele evolui é função das esferas de intercomunicação das quais ele participa (CLAVAL, 1999, p. 65 - 66).
}

Pensar a cultura enquanto elemento espacial para a compreensão das relações sociais nos territórios e a construção das territorialidades a partir da ressignificação e permanência das práticas culturais, nos permitem refletir sobre o construto de relações de poder no cotidiano que entrelaçam-se às formas de organização dos grupos e as ordens estabelecidas em seus modos de vida, além de serem categorias de análise espacial que expressam as simbologias festivas e revelam discursos que evidenciam as relações de pertencimento dos sujeitos ao território construído. Essas relações, produzidas em contextos territoriais de menor escala, não deixam de estarem ligadas a uma lógica espacial de produção de diversos interesses, políticos, econômicos, culturais, entre outros. Sobre essa questão Ratts (2009) aponta que: "O poder exercido pelo Estado e instituições é mais fácil de se ver e agir sobre ele, já que é explícito e propagador de normas e leis que "devem" ser seguidas pela população dominada. Já o poder presente no cotidiano é aquele que não se vê e representa perigo" (RATTS, 2009, p. 88).

O território, nesse sentido, resulta das interações sociais e também influencia essa dinâmica. Nesta discussão, tomamos as concepções de Haesbaert sobre território como fundamentais para o traçado conceitual da pesquisa, tendo em vista as contribuições dadas à compreensão da dimensão cultural dos territórios e das territorialidades quilombolas aqui propostos ${ }^{4}$. Direcionamos nosso pensamento ao território enquanto uma construção

${ }_{4}$ Outras concepções sobre território em suas múltiplas dimensões podem ser apreendidas com base em Saquet (2009), Raffestin (2009), Ribeiro (2003) e Santos (2005). 
coletiva fundada em relações múltiplas de poder e uma multidimensão de territorialidades que não respondem somente pela materialidade das intenções sociais, mas também pelas redes de sociabilidades culturais e identitárias entre os grupos na contiguidade espacial (HAESBAERT, 2009).

Embora tenhamos o interesse de verticalizar nossa discussão para as comunidades quilombolas e as dinâmicas culturais que perpassam seus territórios e respondem pela manutenção das territorialidades dos grupos, não pretendemos generalizar os fatos a ponto de homogeneizar as relações sociais nas comunidades, já que consideramos serem elas frutos de diferentes processos de formação, amparadas por sistemas políticos diferenciados, sobretudo a níveis locais, e detentoras de diversas formas de organização para se fazerem presentes na sociedade, que ainda em grande parte desconhece a trajetória dos grupos tradicionais de modo geral.

Nesse sentido, concordamos com Ribeiro (2003) ao discutir que o território tende a ser conceituado sobre várias perspectivas, e também pelo fato de ser nele que ocorrem, implícita ou explicitamente, as ações localmente organizadas pela sociedade, mas que fazem parte de uma dinâmica espacial mais abrangente.

No intuito de compreender parte dessa dinâmica, propomos, a seguir, caminhos para refletir sobre as manifestações culturais e a construção das territorialidades de alguns grupos quilombolas do estado do Rio Grande do Norte, buscando desvendar as relações de poder simbólico nas ordens espaciais construídas e ressignificadas pelos grupos com/no território, sendo, portanto, passíveis de serem compreendidas a partir de sua espacialização e dos processos de territorialização, que explicitam as singularidades e similitudes.

\section{AS TERRITORIALIZAÇÕES DA CULTURA E A MANUTENÇÃO DAS TERRITORIALIDADES EM COMUNIDADES QUILOMBOLAS DO RIO GRANDE DO NORTE: ELEMENTOS E SISTEMAS SIM- BÓLICOS DOS GRUPOS}

Territorialidade e territorialização são categorias de análise fundamentais no estudo das comunidades quilombolas para a compreensão dos processos culturais dos grupos e suas dimensões material, abarcando os elementos no território concretos que representam pontos de encontro dos grupos ou instrumentos relacionados às suas práticas culturais diversas, e imaterial, relacionada aos valores passados por gerações, ressignificados ao longo do tempo, mas, em grande parte, mantidos através das práticas que reforçam os significados e representatividade. 
A territorialização e a territorialidade, esta última bastante discutida por Haesbaert (2011), são termos correlatos, pois compartilham de sentidos semelhantes, mas se diferenciam no que diz respeito à ideia de processo e de estado, respectivamente. Além disso, a territorialização da cultura enquanto prática social é "uma construção de uma experiência integrada de espaço" (HAESBAERT, 2011, p. 341). Ela pode ser explicada a partir do desenvolvimento de práticas culturais no espaço pelos grupos sociais, um processo contínuo, sujeito a mudanças e permanências, ao passo que a territorialidade determina as formas de ligação com o território a partir de referenciais, sejam eles: símbolos, práticas, sensações, memória, entre outros elementos que servem de meio para a construção de identidades no/com o território.

As territorialidades são sustentadas a partir dos sentidos atribuídos pelos grupos com seus territórios vividos, tanto no sentido da base física, quanto da construção das relações sociais, e podem, também, sofrer rupturas se pensarmos que as relações dos grupos não limitam-se à dimensão física onde está localizada a sua organização social.

Ao debatermos sobre a manutenção das territorialidades e continuação de práticas culturais que marcam as identidades dos grupos quilombolas, não negamos a existência dos conflitos e embates de ideias e práticas divergentes. Comunidades étnicas, em um primeiro momento, podem dar a impressão da convivência fraterna e de relações não conflituosas, mas é necessário que percebamos esses grupos em sua diversidade, uma vez que estão em constante processo de inserção nas políticas públicas sociais e, portanto, ganhando maior visibilidade nos debates políticos e acadêmicos, dando a possibilidade desses grupos adquirirem diferentes níveis de conscientização de sua condição e direitos sociais. Isso reflete a lógica de que nos localismos está presente uma dimensão de ligação afetiva e também conflituosa, reforçando a ideia de que a política neles se territorializa, articulando e ressignificando as relações neles estabelecidas, que, em muitos casos, não são mais estritamente locais. De acordo com Castro (2006):

"A complexidade da tarefa de compreender o mundo, nada simples, e a necessidade de perceber tanto os processos visíveis como aqueles decorrentes da simbologia dos lugares, seus aspectos míticos e suas conotações subjetivas, têm sido também preocupação dos geógrafos (CASTRO, 2006, p. 177).

No Rio Grande do Norte, atualmente existem 21 territórios quilombolas rurais ${ }^{5}$ catalogados pela Fundação Cultural Palmares (Conforme figura 01 a seguir). Sobre alguns

\footnotetext{
O Estado, em seu caráter normatizador, classifica os grupos quilombolas considerando aspectos como: ancestralidade africana e afro-brasileira segundo registros em documentos historiográficos, memória dos grupos, relações de parentesco, dentre outros. No entanto, existem reducionismos e limitações nos critérios de classificação, por não considerarem que esses grupos tiveram diferenciados processos de formação. Há uma série de órgãos mobilizados para tornar mais flexíveis as conceituações sobre as comunidades quilombolas, como a Associação Brasileira de Antropologia, sobretudo pelo fato de muitos documentos se perderem ao longo do tempo, e a memória dos grupos não apresentarem uma linearidade nos fatos (LEITE, 2000).
} 
desses territórios, estudos vêm sendo desenvolvidos no sentido de investigar diversos aspectos, sobretudo culturais ${ }^{6}$. Pelo fato de nossa intenção não ser aprofundar questões históricas sobre o processo de formação das comunidades, mas destacar as práticas culturais relacionadas às festividades de algumas delas, evidenciamos aquilo que consideramos enquanto sistemas simbólicos e seus elementos, configurando formas de territorialização da cultura e manutenção das territorialidades dos grupos.

FIGURA 1: Os vinte e um territórios quilombolas reconhecidos no estado do Rio Grande do Norte

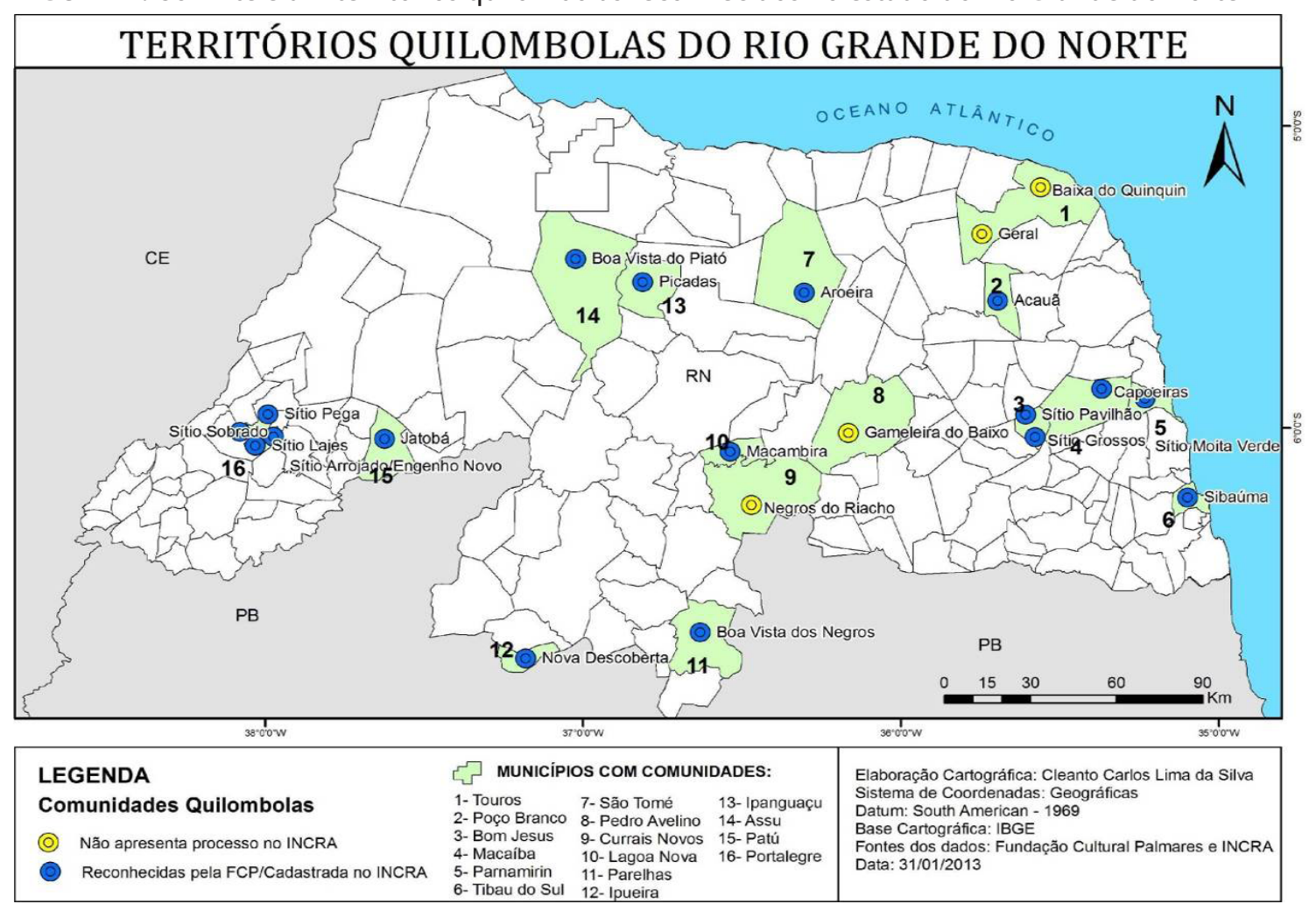

Fonte: Autora (2014).

Em linhas gerais, o processo de territorialização de outras culturas ${ }^{7}$ no Rio Grande do Norte ocorreu de modo mais expressivo através dos colonizadores portugueses, que instituíram nas terras potiguares, valores sociais, hábitos cotidianos (língua e culinária) e práticas religiosas como o catolicismo, divergentes dos costumes das populações nativas indígenas e das populações negras trazidas de outras colônias no Brasil, já que o Rio Grande do Norte não recebeu negros vindos diretamente do continente africano. O processo de imposição de práticas diferenciadas descontruiu em parte, muitos dos costumes das

6 Ver Cavignac (2003 e 2007) Relatório Antropológico da Comunidade Quilombola Boa Vista dos Negros em Parelhas - RN; Morais (2005) estudo sobre relações de parentesco e religiosidade nas comunidades quilombolas do município de Portalegre - RN e Gois (2006) com um estudo sobre as festas do Negros do Rosário em Jardim do Seridó - RN.

Já que as culturas indígenas, que diferiam conforme as tribos, configuram as primeiras culturas do território brasileiro. 
populações subjugadas. Por outro lado, muitas práticas foram ressignificadas com a mistura dos costumes. Segundo Valente (1977), os negros, no processo de escravização durante a colonização no Brasil, foram submetidos à catequização e convertidos à religião católica. Assim, adotaram imagens católicas e as cultuaram, misturando fetichismo com o catolicismo. Muitas das características dos cultos africanos foram inseridas nas práticas do catolicismo, como a realização de procissões às divindades africanas ou aos santos católicos e a construção de santuários para a adoração de seus respectivos santos ou deuses.

O processo de junção de culturas em terras brasileiras constitui um indicativo de que a cultura sempre foi um elemento de poder e de controle político e social. Os sistemas simbólicos das atuais comunidades quilombolas do Brasil e, de modo específico do Rio Grande do Norte, foram e continuam sendo construídos com base nas relações de poder que determinaram, ao longo da história, as mudanças nas suas práticas.

Por sistema simbólico cultural no âmbito das comunidades quilombolas rurais, entendemos os objetos e as práticas que o alimentam, dando sentido e respondendo pela permanência das tradições dos grupos quilombolas. Mesmo tendo passado por transformações em decorrência da extensão das redes de sociabilidade com outros grupos, percebemos que os símbolos e as identificações dos grupos com a sua cultura são mantidos por um poder simbólico que, de maneiras diferenciadas, permite a sua continuidade. As festas, sobretudo as religiosas, e os elementos simbólicos existentes em seu desenvolvimento, estão repletos de sentidos que merecem atenção por expressarem valores simbólicos que reforçam as identidades dos grupos envolvidos.

Um fato importante a ser destacado é que o catolicismo e as intervenções jesuítas na cultura dos grupos indígenas e negros com o intuito de catequizá-los deixaram uma herança para as comunidades do Rio Grande do Norte. O catolicismo historicamente imposto aos povos originários e aos negros escravizados, omitiu ao longo do tempo as características das danças africanas e de seus rituais. Atualmente, quase todas as comunidades do estado do Rio Grande do Norte têm como padroeiro santos católicos, que cultuados em algumas comunidades quilombolas apresentam traços de um sincretismo religioso afro-brasileiro, seja pela presença de batucadas que embalam os louvores aos santos, o uso de fitas coloridas enfeitando as suas imagens e as procissões que também vêm de tradições afro-brasileiras. Destacamos as festas religiosas por serem representações dos sistemas simbólicos nas comunidades que tivemos conhecimento no estado até o presente momento, são elas: comunidades Pêga e Arrojado, ambas situadas no município de Portalegre; Boa Vista dos 
Negros no município de Parelhas e a comunidade Jatobá localizada no município de Patu

Os sistemas simbólicos elaborados pelos grupos compõem, dentro da perspectiva de território em Haesbaert, elementos que interligam as redes de sociabilidades culturais dos grupos, e funcionam a partir dos significados atribuídos às práticas culturais pelos quilombolas. Devemos considerar que houve e continua havendo transformações nas representações e práticas dos grupos negros que, mesmo apresentando influências católicas mais evidentes, manifestam a presença de alguns elementos da cultura africana, a citar as práticas das rezadeiras e curandeiras ainda existentes, além do uso de fitas para enfeitar os santos, as procissões que são herança de muitos rituais africanos, bem como os batuques e as zabumbas nas festas de São Gonçalo e na dança do Espontão e Coroação dos Reis. A seguir vemos figuras dos festejos citados:

FIGURA 2 - Dança do Espontão e a Coroação dos Reis. Comunidade Boa Vista dos Negros

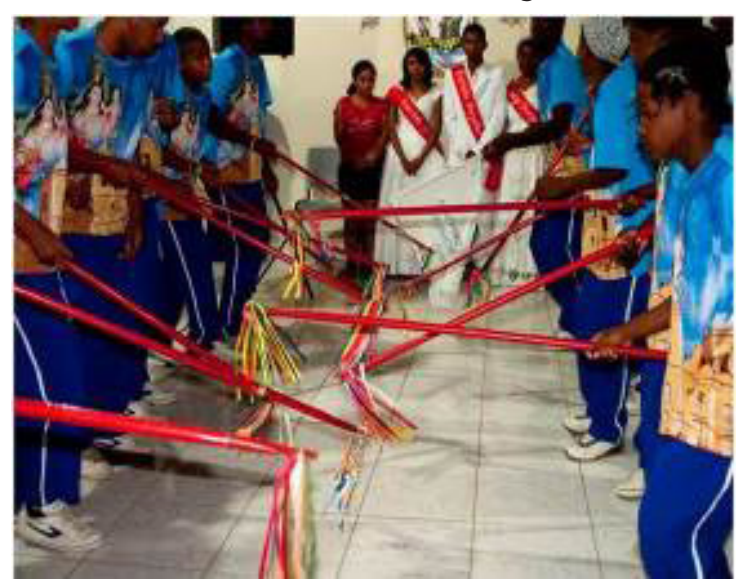

Fonte: AC Junior, 2013
FIGURA 3 - Procissão de São Gonçalo. Comunidade Pêga

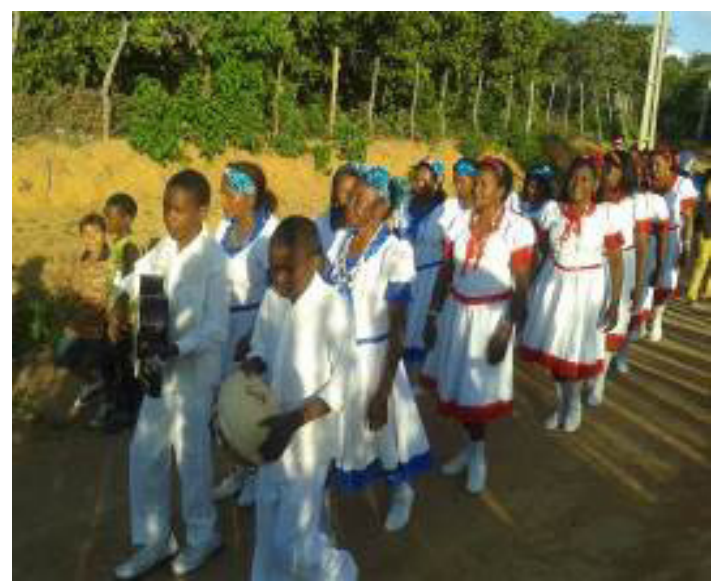

Fonte: Autor, 2014

8 Alguns trabalhos foram desenvolvidos sobre as comunidades destacadas. Ver: Cavignac (2003) Moraes (2003 e 2005), Pereira e Dozena (2015 e 2014) e Assunção (2009). 
FIGURA 4 - Dança de São Gonçalo Comunidade Arrojado

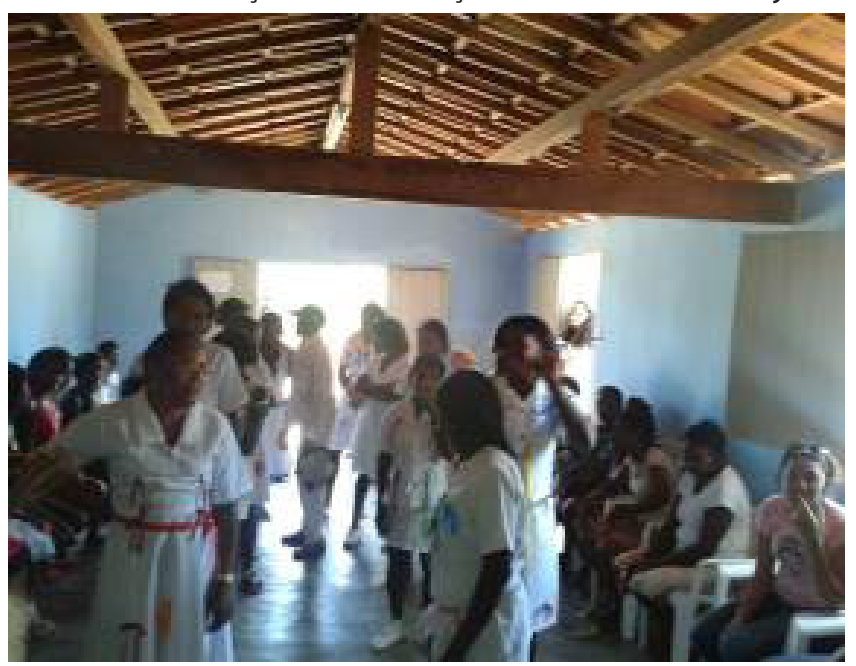

Fonte: Autor, 2014.

Embora o catolicismo seja, atualmente, a religião predominante em muitas comunidades quilombolas no Brasil, é preciso considerar que, nesses grupos, os festejos compõem sistemas simbólicos diferenciados, construídos a partir dos significados que os grupos atribuem às suas festas e que respondem pelas diferentes territorialidades construídas e mantidas nos grupos a partir do fortalecimento e das rupturas em suas práticas culturais 9 .

As festas de São Gonçalo ${ }^{10}$ ocorridas nas comunidades Pêga e Arrojado em Portalegre $\mathrm{RN}$, município situado a oeste do estado do Rio Grande do Norte, ocorre anualmente no dia 24 de janeiro. Nas referidas comunidades, São Gonçalo é cultuado de maneiras diferentes, embora tenham elementos semelhantes. Os grupos são compostos por quatorze pessoas, das quais doze são mulheres, as dançadeiras, e dois são homens, chamados de tocadores. As imagens cultuadas dos santos são diferentes, e o grupo de São Gonçalo que antigamente era formado por pessoas das duas comunidades, em meados de 2010 fragmentou-se em dois grupos, formando o grupo de São Gonçalo do Arrojado e o grupo do Pêga. De acordo com relatos de alguns moradores das comunidades, o grupo se desintegrou por desavenças de opiniões entre seus membros. Isso reforça a ideia sobre as fragmentações das relações

9 Um exemplo válido de ser citado é que atualmente na comunidade Arrojado em Portalegre - RN, o festejo a São Gonçalo não está sendo realizado. Parte dos jovens da comunidade não se empenham em participar da tradição que necessita de dançadeiras e tocadores mais jovens, tendo em vista que quase todas que participavam já apresentam idade avançada. Há uma proposta de alguns moradores e da Secretaria de Cultura do município em incentivar a formação de um novo grupo, mas as medidas ainda não foram tomadas.

${ }^{10}$ A dança de São Gonçalo chegou à serra de Portalegre em 1790, trazida pelos colonizadores portugueses e era dançada pelos índios da tribo Pêga (FERREIRA apud MORAIS, 2005). Na época de culto ao santo, foram agregados valores da cultura africana e indígena segundo Silva (1953), que assistiu a uma apresentação da dança na cidade de Portalegre em 1938 (MORAIS, 2005). 
e diferentes posicionamentos que os indivíduos estão sujeitos a tomar mesmo quando inseridos em uma realidade aparentemente homogênea.

A festa do Rosário compõe outro sistema simbólico que, assim como os demais, dinamizam o cotidiano dos grupos que o constrói. Ela é realizada nos municípios de Caicó e Jardim do Seridó nos dias 30 e 31 de dezembro e $1^{\circ}$ de janeiro. Em sua programação, há cortejos da imagem para a chegada na Igreja Matriz de Nossa Senhora da Conceição, recitação do Rosário de Nossa Senhora e procissões com as batucadas e espontões (bastões enfeitados) dos Negros do Rosário, como ilustramos anteriormente na figura 2. Em seguida, há o hasteamento das bandeiras quando a festa se inicia. Nos dias 30 e 31 se realizam duas novenas, e no dia $1^{\circ}$ de janeiro, dia da festa em Jardim do Seridó, ocorre a reunião das irmandades negras ${ }^{11}$, missa e procissão de encerramento (GOIS, 2006).

Por fim, de modo a exemplificar as festas nas comunidades enquanto meios de construção, permanência e transformação das territorialidades dos grupos, destacamos a festa de São Benedito na comunidade quilombola Jatobá em Patu. Abaixo temos a foto de um dos momentos do festejo. A festa tem início anualmente no dia 5 de outubro e dura três dias com a realização de novenas e encerramento com uma procissão com a imagem do santo.

FIGURA 5 - Procissão de São Benedito na Comunidade Jatobá

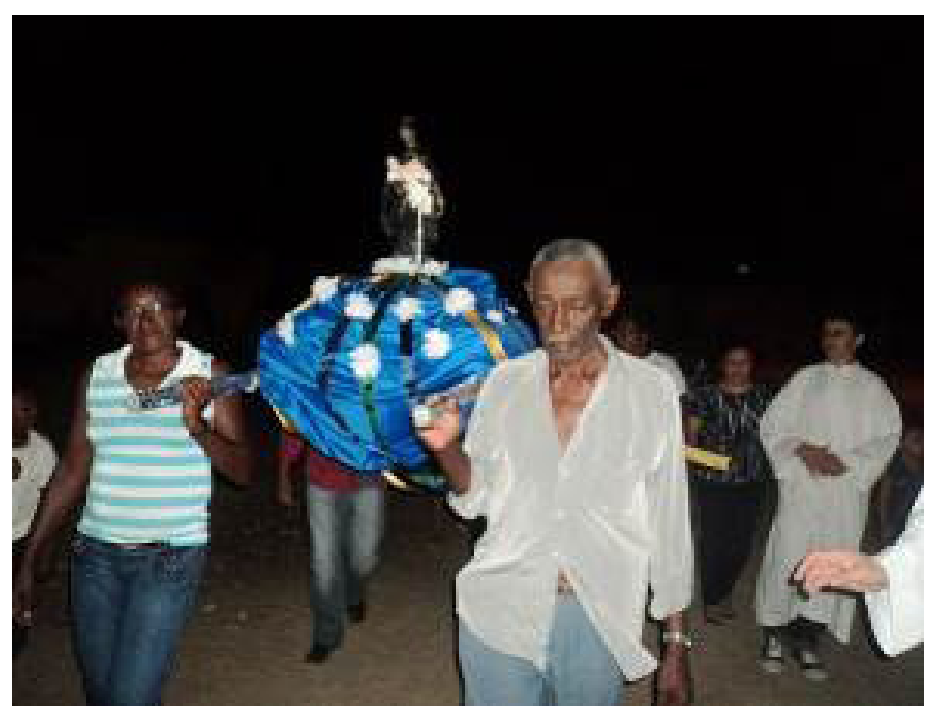

Fonte: Edno Azevedo, 2012

\footnotetext{
${ }^{11}$ De acordo com Cavignac (2008), as irmandades negras presentes em todo o Brasil e a festa de Nossa Senhora do Rosário das irmandades negras começaram a ocorrer no Nordeste a partir do final do Século XVII, com a coroação dos Reis do Congo em Recife em 1674. No Seridó, as irmandades começaram a se formar com a cultura do algodão no século XIX.
} 
Diferentemente do que ocorre nas outras comunidades aqui apresentadas, na festa de São Benedito da Comunidade quilombola Jatobá, não há realização de danças com batuques ou pandeiros. Mas, os poucos elementos afro-brasileiros aqui já discutidos apontam para a permanência de algumas tradições. Nas três comunidades apresentadas, vimos que a igreja católica exerce um poder centralizador nas festividades dos grupos, a presença dos párocos das cidades em todos os momentos das festas, constitui resultado de um longo processo de controle desses grupos no decorrer da história. Vale destacar que a festa de modo geral sempre foi uma forte característica cultural de grupos tradicionais, sobretudo os de matriz africana, ainda que devam ser consideradas as mudanças ocorridas e que ainda continuam a influenciar as diferentes formas de interação desses grupos. De acordo com Amaral:

A festa funciona como mediadora entre os anseios individuais e coletivos, mito e história, fantasia e realidade, passado e presente, presente e futuro, nós e os outros, [...] mediando ainda os encontros culturais e absorvendo, digerindo e às vezes transformando em pontes os opostos inconciliáveis (AMARAL, 1998 apud MAIA, 1999, p. 196).

A festa constitui um dos elementos pertencentes aos diversos grupos sociais. Por suas peculiaridades, a festa e a cultura, de modo geral, podem ser entendidas como os significados elaborados e reelaborados pelos grupos, com base em suas relações sociais, em um dado espaço. As festas nessas e em todas as comunidades constituem aquilo que Corrêa (2008) chama de itinerários simbólicos. Eles compõem rituais regulares ou não-regulares, podendo ocorrer em datas definidas, tradições locais, datas festivas ou esporadicamente. No geral, apresentam percursos consagrados pelas práticas socioculturais, indicando a força de determinados itinerários. Essa discussão evidencia a mobilidade que a cultura apresenta no espaço através dos sujeitos que a praticam, e dos elementos utilizados para a materialização do seu poder de atuação política e simbólica.

\section{CONSIDERAÇÕES FINAIS}

A discussão aqui apresentada configura-se como uma proposta de entendimento da ampliação teórica-metodológica da geografia, permitindo que objetos de pesquisa como este que foi apresentado fosse debatido na perspectiva da geografia cultural. Como vimos, dependendo da maneira pela qual o pesquisador aborde determinados temas é possível que se revelem elementos de caráter político, além de relações de conflito que se desenvolvem na coletividade desconstruindo a ideia de homogeneidade que ainda permeia alguns estudos sobre comunidades quilombolas. 
O conceito de território aqui apresentado com base em Haesbaert, apresenta um conteúdo cultural e político fundamentais para entendermos a cultura dessas comunidades enquanto produto e produtora de representações do poder nos territórios, sendo possíveis de serem compreendidas em sua dimensão espacial. Os sistemas simbólicos culturais, a materialização de sua cultura nos territórios e as formas de organização desses grupos na defesa de seus direitos frente ao poder público, sobretudo em instância municipal, estão constituídos de forças políticas que mantém as territorialidades dos indivíduos. Os conflitos, ainda que mínimos aqui apresentados, apontam para as fragmentações que ressignificam o conceito arcaico de comunidade, enquanto ambiente de homogeneidade de ideias e ações. Ressaltamos que comunidades dessa natureza ainda se constituem como tema novo na Geografia, sendo mais comumente abordadas sobre a perspectiva da Antropologia, sendo, dessa forma, um desafio teórico e metodológico de pesquisa para aqueles que as têm como foco de estudo.

\section{REFERÊNCIAS}

1. ALEXANDRE, Fernanda; OLIVEIRA, Sandra de Fátima. Fenomenologia e memória: novos aportes para a práxis da EA. In: Revista Eletrônica do Mestrado em Educação Ambiental - Revista do PPGEA/FURG-RS. Disponível em: http://pt.scribd.com/doc/51641008/ FENOMENOLOGIA-E-MEMORIA. Acesso em: novembro, 2015.

2. CASTRO, Iná Elias de. Imaginário político e território: natureza, regionalismo e representação. In:____ GOMES, Paulo César da Costa; CORRÊA, Roberto Lobato. (Org). Explorações geográficas: percursos no fim do século. 2.ed. Rio de Janeiro: Bertrand Brasil, 2006, p. 155 - 196.

3. CAVIGNAC, Julie Antoinette. Os “Troncos Velhos” e os "Quilombinhos” Memória Genealógica, Território e Afirmação Étnica Em Boa Vista Dos Negros (RN). In: Ruris, volume 2, número 2, setembro de 2008. Disponível: http://www.ifch.unicamp.br/ceres/2008Os_Troncos_velhos_e_ os_Quilombinhos.pdf. Acesso: novembro, 2015.

4. MEL MEL José Antonio Fernandes de; RODRIGUES JUNIOR, Gilson José; SANTOS, Sebastião Genicarlos dos. Relatório Antropológico da Comunidade Quilombola de Boa Vista dos Negros - RN. Convênio UFRN/INCRA - RN. Natal, 2007.

5. _ _ A etnicidade encoberta: 'Índios' e 'Negros' no Rio Grande do Norte. In: Revista de humanidades. Publicação do Departamento de História e Geografia da Universidade Federal do Rio Grande do Norte. Centro de Ensino Superior do Seridó - Campus de Caicó. V.4 - N.8 - abr./set. de 2003- Semestral. Disponível em: http://www.periodicos.ufrn.br/ojs/index.php/ mneme/article/view/167/157. Acesso em: novembro, 2015.

6. CLAVAL, Paul. As abordagens da geografia cultural. In: Castro, Iná Elias de; Gomes, GOMES, Paulo César da Costa; CORRÊA, Roberto Lobato. (Org). Explorações geográficas: percursos no fim do século. 2.ed. Rio de Janeiro: Bertrand Brasil, 2006, p. 89 - 117. 
7. A geografia cultural: o estado da arte. In: ROSENDAHL, Zeny; CORRÊA, Roberto Lobato. Manifestações da cultura no espaço. Rio de Janeiro: EdUERJ, 1999, p. 59 - 97.

8. CORRÊA, Roberto Lobato. Espacialidade da cultura. In: Oliveira, Márcia P.; COELHO, Maria C. N.; CORREA, Aurenice M. (Orgs.). O Brasil, a América e o Mundo: espacialidade contemporânea. Rio de Janeiro: Lamparina/FAPERJ, 2008, p.301-352.

9. GOIS, Diego Marinho de. Entre estratégias e táticas: enredos das festas dos negros do rosário em Jardim do Seridó - RN. Monografia apresentada ao Curso de História) - Universidade Federal do Rio Grande do Norte, Campus Caicó, 2006).

10. HAESBAERT, Rogério. Dilema de conceitos: espaço-território e contenção territorial. In: SAQUET, Marcos Aurélio; SPOSITO, Eliseu. Sposito. (Orgs.). Territórios e territorialidades: teorias, processos e conflitos. São Paulo: Expressão Popular: UNESP. Programa de PósGraduação em Geografia, 2009, p. 95 - 120.

11. _____ Definindo território para entender a desterritorialização. In: O mito da desterritorialização: do "fim dos territórios" à multiterritorialidade. Rio de Janeiro: Bertrand Brasil, 2011, p. 35 - 98.

12. LEITE, Ilka Boaventura. Os quilombos no Brasil: questões conceituais e normativas. Etnográfica, vol. IV (2), 2000, p. 333-354.

13. MAIA, Carlos Eduardo Santos. Ensaio interpretativo da dimensão espacial das festas populares: proposições sobre festas populares. In: ROSENDAHL, Zeny; CORRÊA, Roberto Lobato. Manifestações da cultura no espaço. Rio de Janeiro: EdUERJ, 1999, p. $191-218$.

14. MORAIS, Glória Cristiana de Oliveira. Entre parentes: cotidiano, religiosidade e identidade na serra de Portalegre/RN. Dissertação de Mestrado do Programa de Pós-Graduação em Ciências Sociais da UFRN, 2005. Disponível em: http://bdtd.bczm.ufrn.br/tedesimplificado//tde_busca/ processaArquivo.php? codArquivo=241\&PHPSESSID=282d95edf424fb76758832f632a 818b8. Acesso em: novembro, 2015.

15. RATTS, Alecsandro José Prudêncio. A geografia entre as aldeias e os quilombos: territórios etnicamente diferenciados. In: ALMEIDA, Maria Geralda de; RATTS, Alecsandro JP (Org.). Geografia: leituras culturais. Goiânia: Alternativa, 2003, p. 29 - 48.

16. ___ _ _ SOUZA, Lorena Franciso de. Espaço, cultura e poder: gênero e raça em análise na geografia. In: Ateliê Geográfico. Vol. 3 - No 1. Goiânia - GO, 2009, p. 97 - 110. Disponível em: file:///C:/Users/marcilio/Downloads/6257-23364-3-PB.pdf. Acesso em: novembro, 2015.

17. RIBEIRO, A. C. T Pequena reflexão sobre categorias da teoria crítica do espaço: território usado, território praticado. In: SOUZA, M. A de. [et al.]. Território brasileiro: usos e abusos. Campinas: Edições Territorial, 2003, p. 29 - 40.

18. ROSA, Lucas Aidar. A atualidade da obra "Geografia Humana", de Jean Brunhes, e suas contribuições para a Ciência Geográfica atual. Departamento de Geografia - FFLCH. Universidade de São Paulo, 2010. Disponível em: https://uspdigital.usp.br/siicusp/ cdOnlineTrabalhoVisualizarResumo? numeroInscricaoTrabalho $=4615 \&$ numeroEdicao $=17$. Acesso em: outubro, 2015. 
19. SEEMANN, Jörn. "Cartografias culturais" na geografia cultural: entre mapas da cultura e a cultura dos mapas. In: Boletim Goiano de Geografia. Universidade Federal de Goiás. Instituto de estudos sócio-ambientais/geografia. Vol. 21 - N o 2. Jul/Dez. 2001. Disponível em: http:// www.revistas.ufg.br/index.php/bgg/article/viewFile/4214/3687. Acesso em: outubro, 2015.

20. VALENTE, Waldemar. Sincretismo religioso afro-brasileiro. São Paulo: Companhia editora nacional, 1977.

Artigo recebido em 31 de novembro de 2015.

Artigo aceito em 22 de dezembro de 2015. 